\title{
Correlative analysis of lung CT findings in patients with Birt-Hogg-Dubé Syndrome and the occurrence of spontaneous pneumothorax: a preliminary study
}

\author{
Jinjing Yang ${ }^{1}$, Xiaowen $\mathrm{Hu}^{2}$, Junjun $\mathrm{Li}^{1}$, Guofeng Zhang ${ }^{2}$, Yaqiong $\mathrm{Ge}^{3}$ and Wei Wei ${ }^{\text {* }}$
}

\begin{abstract}
Background: The diagnosis of patients with Birt-Hogg-Dubé (BHD) syndrome is always delayed (even for more than 10 years). Improving the understanding and diagnosis of this disease is vital for clinicians and radiologists. In this study we presented the chest computed tomography (CT) findings of BHD syndrome and offered suggestions for BHD cases with spontaneous pneumothorax.

Methods: Twenty-six BHD patients from 11 families (10 men, 16 women; mean age: 46 \pm 12 years, 20-68 years) were included. The clinical features of the patients included pneumothorax, renal lesions, and skin lesions. Twenty-three patients underwent chest $\mathrm{CT}$ imaging. The cyst condition of each patient derived from reconstructed chest $\mathrm{CT}$ imaging was recorded, including the cyst number, size, volume, pattern, and distribution.

Results: Pneumothorax occurred in 54\% (14/26) of patients. Among them, 43\% (6/14) had pneumothorax more than twice. However, typical skin and renal lesions were absent. Four patients had renal hamartoma. CT showed that 23 (100\%) patients had lung cysts. Pulmonary cysts were bilateral and multiple, round, irregular, or willow-like. And $93.6 \%$ of the large cysts (long-axis diameter $\geq 20 \mathrm{~mm}$ ) were under the pleura, and near the mediastinum and spine. The long-axis diameter, short-axis diameter and volume of the largest cysts were associated with the occurrence of pneumothorax (all $\mathrm{P}<0.05$ ).
\end{abstract}

Conclusions: Chest CT imaging can reveal some characteristic features of BHD syndrome. The occurrence of pneumothorax in BHD patients is closely related to their pulmonary cystic lesions.

Keywords: Computed tomography, Birt-Hogg-Dubé syndrome, Pneumothorax, Lung cysts

\section{Background}

Spontaneous pneumothorax is a clinical emergency often characterized by chest tightness and dyspnea. Traditionally, spontaneous pneumothorax is divided into primary and secondary spontaneous

\footnotetext{
*Correspondence: weiweill@126.com

${ }^{1}$ Department of Radiology, The First Affiliated Hospital of USTC, Division

of Life Sciences and Medicine, University of Science and Technology

of China, Hefei 230001, Anhui, China

Full list of author information is available at the end of the article
}

pneumothorax. Primary spontaneous pneumothorax refers to the case without a prior known lung disease [1]. Patients with primary spontaneous pneumothorax are often slender and have a low body mass index. Secondary spontaneous pneumothorax may occur in many pulmonary diseases, such as tuberculosis, cystic fibrosis, primary lymphangioleiomyomatosis, Langerhans cell histiocytosis, and Birt-Hogg-Dubé (BHD) syndrome. Among these, chronic obstructive pulmonary disease and cystic fibrosis are more common. In clinical 
work, patients often suffer recurrent pneumothorax, and surgeons tend to make more efforts in treating patients and pay less attention to the underlying causes of the disease.

This study aimed to investigate the characteristics of lung lesions of BHD patients and the relationship between the occurrence of pneumothorax and lung cyst features through chest computed tomography (CT) images in these patients. We propose a chest CT examination, not just a chest X-ray, should be conducted for BHD patients and the investigation needs to be extended to family members.

\section{Methods}

\section{Enrollment of patients}

A total of 26 BHD patients from 11 families were selected by BHD screening (including chest CT, gene detection, or a dermatological examination). The clinical data of these patients were collected, including lung, skin, and kidney lesions, pneumothorax, and smoking history.

\section{CT data}

Among the 26 patients, 23 underwent a chest CT scan (Neu Viz 128) without the contrast agent. The scanning parameters were as follows: tube voltage, $120 \mathrm{kVp}$; tube current, $70 \mathrm{~mA}$; slice thickness, $1.25 \mathrm{~mm}$; FOV $400 \times 400 \mathrm{~mm}$. CT images were reviewed by two thoracic radiologists (J.Y and J.L with 8 and 6 years of experience in thoracic imaging, respectively) with consensus reached. The chest $\mathrm{CT}$ images of these 23 patients were retrospectively analyzed, including bilateral pulmonary cyst distribution, cyst shape, the diameter and volume of the largest cyst, the total number of cysts in different size categories (long-axis diameter $\leq 10 \mathrm{~mm}, 10-20 \mathrm{~mm}$, and $\geq 20 \mathrm{~mm}$ ), the number of subpleural cysts in these size categories, and the volume of cysts with a long-axis diameter $\geq 20 \mathrm{~mm}$. The term "subpleural" referred to the area within $10 \mathrm{~mm}$ from the mediastinum, chest wall, and interlobar fissure. Assuming that the cyst was a long oval shape, the cyst volume was calculated using the following formula: volume $=4 / 3 \pi a b^{2}$ ( $\mathrm{a}$ : half of the longest diameter, b: half of the length of the shorter diameter) [2] Intraclass correlation efficient (ICC) was used to evaluate the consistency of the analystic results by the two physicians, and the results with ICC $\geq 0.8$ were used for further analysis.

$\mathrm{R}$ statistical software (v. 3.5.1; https://www.Rproj ect.org) was used for analysis. The Spearman analysis method was applied to examine the correlation between imaging characteristics of pulmonary cysts and the occurrence of pneumothorax.

\section{Results}

Clinical data

Genetic tests were performed on 24 patients and folliculin (FLCN) mutations were confirmed. Another 2 patients did not undergo genetic tests, but their firstdegree relatives were confirmed to have gene mutations; chest CT examination revealed multiple cystic lesions in both lungs of these two patients, which met the diagnostic criteria of BHD, and the diagnosis of BHD was made. The 26 patients ( 10 men and 16 women) were aged 20-68 years, with a mean age of $46 \pm 12$ years. Pneumothorax occurred in $54 \%(14 / 26)$ of the patients, among whom $43 \%$ had pneumothorax twice or more times, with the highest number of four times. The youngest onset age of pneumothorax was 19 years old. A total of $79 \%$ (11/14) of patients with a history of pneumothorax were non-smokers. Four patients had complicated lung tumors (including lung cancer and alveolar cell tumor). None of the patients had typical skin or kidney lesions. Renal hamartoma occurred in four cases and skin epidermoid cyst in two cases.

\section{CT data}

The final study population included 23 subjects with a total of 2323 lung cysts documented by chest CT examination. Bilateral and multiple pulmonary cysts were found in these patients. The size of the cysts varied, with the diameter ranging from 4 to $110 \mathrm{~mm}$. The cysts were mostly of irregular, willow leaf-like, round, or oval shapes (Fig. 1). Some larger cysts near the mediastinal spine

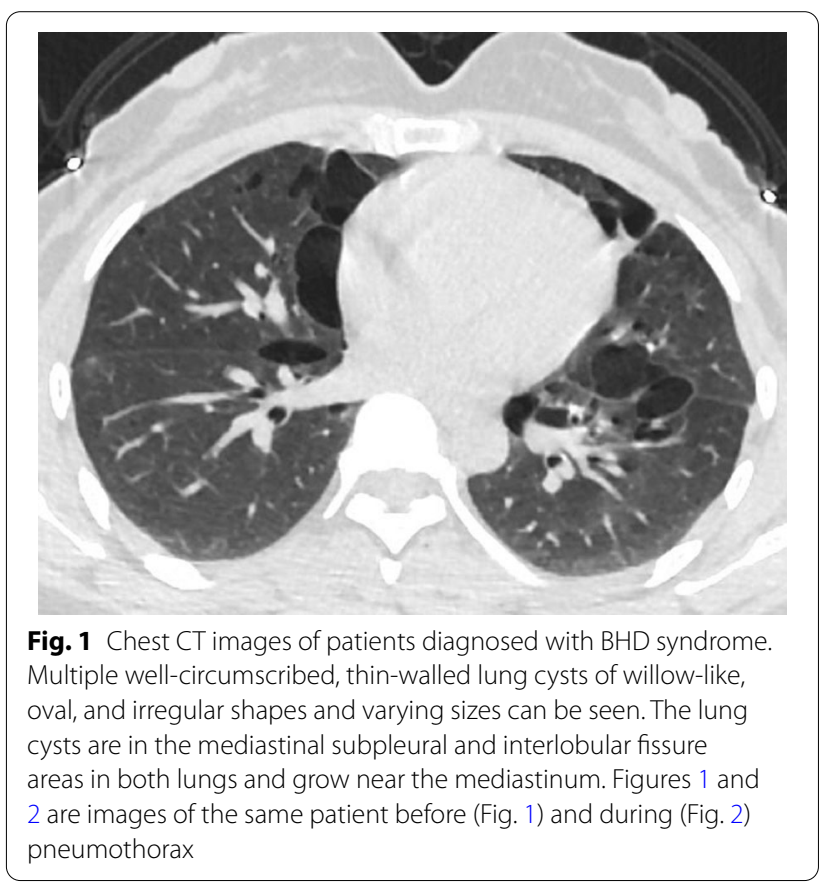




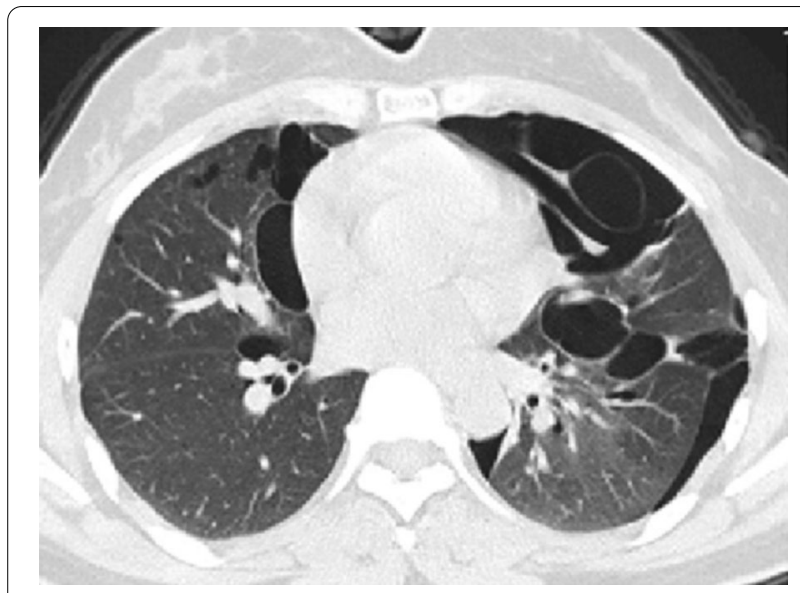

Fig. 2 Chest CT images of patients diagnosed with BHD syndrome. Multiple well-circumscribed, thin-walled lung cysts of willow-like, oval, and irregular shapes and varying sizes can be seen. The lung cysts are in the mediastinal subpleural and interlobular fissure areas in both lungs and grow near the mediastinum. Figures 1 and 2 are images of the same patient before (Fig. 1) and during (Fig. 2) pneumothorax

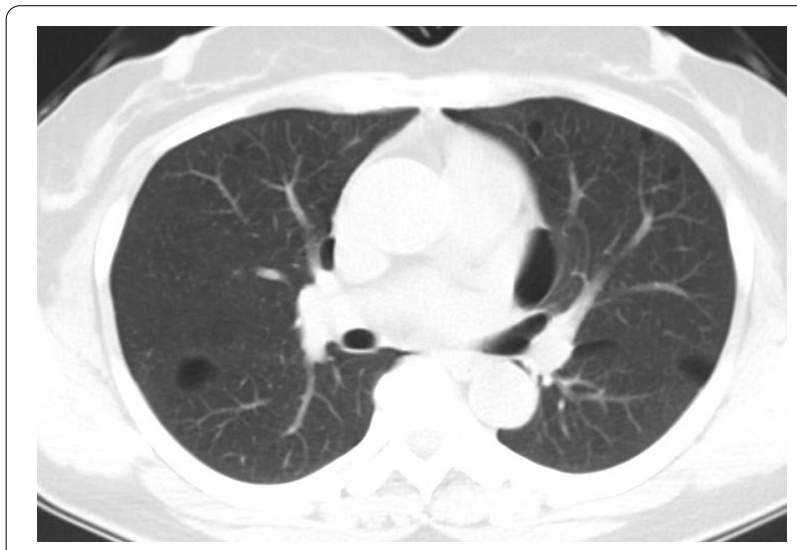

Fig. 3 Chest CT images of patients diagnosed with BHD syndrome. Multiple lung cysts of willow-like, oval, and irregular shapes and varying sizes can be seen. The lung cysts are in the mediastinal subpleural and interlobular fissure areas in both lungs and grow near the mediastinum showed plastic changes along the mediastinum and spine. Most cysts were under the pleura of both lungs (Figs. 1, 2 , 3), subpleural sacs accounting for $76.3 \%(1772 / 2323)$ of pulmonary sacs. About $93.6 \%$ (161/172) of cysts with the long-axis diameter $\geq 20 \mathrm{~mm}$ were distributed under the pleura (Table 1), and the mediastinal subpleural ones in accounted for the highest proportion (48.4\%; Table 2). Multiple cysts were also observed in the subpleural area of bilateral interlobar fissures (Fig. 4).

For cysts in both lungs, the number of cysts with longaxis diameter $\leq 10 \mathrm{~mm}$ accounted for $75.8 \%(1760 / 2323)$, those with long-axis diameter between 10 and $20 \mathrm{~mm}$ accounted for $16.8 \%(391 / 2323)$, and those with long-axis diameter $\geq 20 \mathrm{~mm}$ accounted for $7.4 \%(172 / 2323)$.

Spearman analysis showed that the long-axis diameter, short-axis diameter, and volume of the largest cysts were significantly associated with the occurrence of pneumothorax (all $\mathrm{P}<0.05$; Table 3 ). There were no significant differences in the total number of cysts in both lungs, and the total numbers of cysts in the left, right, and both lungs with the cysts' long-axis diameter $\leq 10$, $10-20$, and $\geq 20 \mathrm{~mm}$ between the pneumothorax group and non-pneumothorax group. There were no significant differences in the number of subpleural lung cysts with a long-axis diameter $\leq 10,10-20$, and $\geq 20 \mathrm{~mm}$ among the mediastinum, chest wall, and interlobar pleura. The total long-axis diameter, short-axis diameter, and volume of the cysts with a long-axis diameter $\geq 20 \mathrm{~mm}$ showed no obvious correlation with the occurrence of pneumothorax.

\section{Discussion}

BHD syndrome is a rare autosomal dominant genetic disease, which is often misdiagnosed as pulmonary bullae. In this study, we included 26 patients with BHD and observed their chest CT and clinical features. The cysts of BHD patients were mainly of round and irregular shape, characterized by subpleural distribution. About $54 \%$ of BHD patients developed pneumothorax, and the occurrence of pneumothorax was related to the long-axis diameter, short-axis diameter and volume of the largest cysts $(\mathrm{P}<0.05)$.

Table 1 Percentage of mediastinal, chest wall, and interlobar subpleural cysts of different sizes in relation to the size of cysts in both lungs

\begin{tabular}{llll}
\hline & Mediastinal subpleural & Chest wall subpleural & Interlobar subpleural \\
\hline long-axis diameter $\leq 10 \mathrm{~mm}$ & $23.3 \%(410 / 1760)$ & $33.5 \%(590 / 1760)$ & $16.3 \%(287 / 1760)$ \\
long-axis diameter $10 \mathrm{~mm}-20 \mathrm{~mm}$ & $38.1 \%(149 / 391)$ & $32.7 \%(128 / 391)$ & $12.0 \%(47 / 391)$ \\
long-axis diameter $\geq 20 \mathrm{~mm}$ & $45.3 \%(78 / 172)$ & $29.1 \%(50 / 172)$ & $19.2 \%(33 / 172)$ \\
\hline
\end{tabular}


Table 2 Percentage of mediastinal, chest wall, and interlobar subpleural cysts of different sizes in relation to the size of cysts of subpleural distribution

\begin{tabular}{llll}
\hline & Mediastinal subpleural & Chest wall subpleural & Interlobar subpleural \\
\hline long-axis diameter $\leq 10 \mathrm{~mm}$ & $31.9 \%(410 / 1287)$ & $45.8 \%(590 / 1287)$ & $22.3 \%(287 / 1287)$ \\
long-axis diameter $10 \mathrm{~mm}-20 \mathrm{~mm}$ & $46.0 \%(149 / 324)$ & $39.5 \%(128 / 324)$ & $14.5 \%(47 / 324)$ \\
long-axis diameter $\geq 20 \mathrm{~mm}$ & $48.4 \%(78 / 161)$ & $31.1 \%(50 / 161)$ & $20.5 \%(33 / 161)$ \\
\hline
\end{tabular}

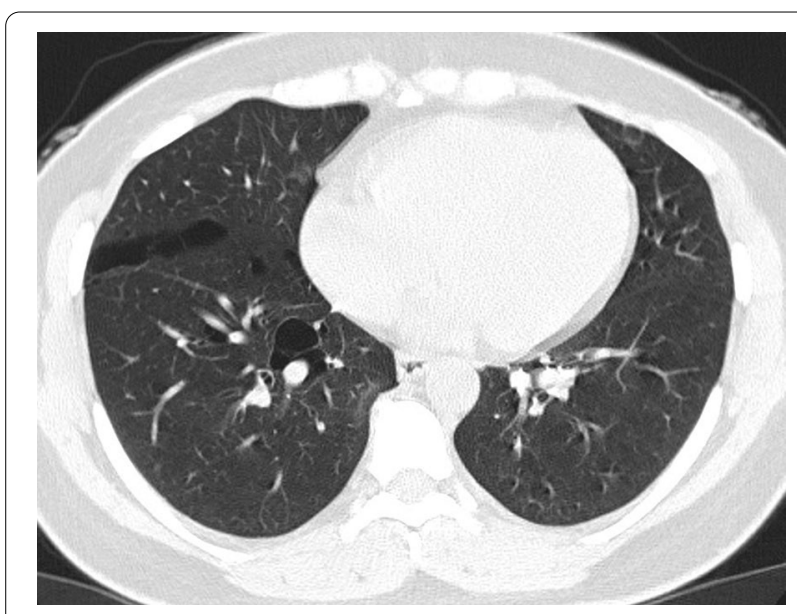

Fig. 4 Chest $C T$ images of patients diagnosed with BHD syndrome. Multiple lung cysts ofvarying sizes can be seen. The lung cysts are in the interlobular fissure areas

The mutation of the folliculin $(F L C N)$ gene is closely related to the occurrence of BHD syndrome. BHD syndrome is named after the Canadian doctors Birt, Hogg, and Dubé who reported a family with fibrofolliculomas, trichodiscomas, and acrochordons in 1977. Benign tumors of the skin, various types of renal tumors, and multiple lung cysts are the characteristic manifestations of BHD syndrome. Skin damage mainly manifests as fibrofolliculomas, which may be accompanied by trichodiscomas and acrochordons. Mixed oncocytoma or chromophobe cell tumor is a typical renal manifestation [3]. Epidemiological data have shown that the incidence of tumors in the skin and lungs is higher than that of renal tumors [4]. Skin lesions and FLCN gene mutations are classified as the main diagnostic criteria of BHD syndrome [5]. There are ethnic differences in the clinical manifestations of BHD syndrome. Previous studies have shown that $>80 \%$ of BHD syndrome cases in Europe and the United States have specific skin lesions, while the incidence of skin lesions and renal tumors in Asians is low [6-8]. There were no typical skin and kidney lesions in the cases included in our study.
A majority of patients with BHD syndrome have pulmonary cysts [2, 9-11]. In our study, lung cysts were found in all the $23(100 \%)$ patients' chest CT images. The cysts in the lungs of all patients were bilateral and multiple, with different sizes. The larger cysts were often irregular, while the smaller cysts were mostly round or oval. Some of the larger cysts near the mediastinal spine showed plastic changes along the mediastinum and spine, which may have been caused by high pressure in the capsule, with limited growth space. In the current study, $76.3 \%$ of the cysts were distributed under the pleura of both lungs, and $93.6 \%$ of the cysts with a long-axis diameter $>20 \mathrm{~mm}$ were distributed under the pleura, especially near the mediastinum (48.4\%). Furuya and Koga et al. $[12,13]$ studied the unruptured pulmonary cysts associated with BHD syndrome and found that the cyst wall expanded toward the visceral pleura and was partially embedded in parenchyma, interlobular septum, and bronchovascular bundles. Additionally, enlarged cysts were segmented by the alveolar wall and deeply embedded in the interlobular septum. These complex structures were usually accompanied by varying degrees of chronic inflammatory cell infiltration, suggesting possible inflammation-induced development of cysts. Cystic alveoli and fusion of the epithelium of the cyst to the mesenchyme are indicators for BHD-associated lung lesions [14]. BHD syndrome-associated cysts are originally located close to the interlobular septum or subpleura [14], which could explain why $76.3 \%$ of the cysts on chest CT images in our study were under the pleura of both lungs. Our study showed that in addition to subpleural cysts of the mediastinum and chest wall, multiple cysts were also observed in the bilateral interlobar pleura. This finding is consistent with the above-mentioned pathological results. Despite the existence of multiple cysts in the lungs, the patients' pulmonary function remains unaffected [15]. In our study, a BHD patient with normal pulmonary function had experienced pneumothorax for four times and received surgical treatment.

Lung-associated symptoms are usually the first to appear in patients with BHD syndrome. Pneumothorax may be the first and only symptom that causes most patients with BHD syndrome to visit the hospital. Though classified as minor criteria for the diagnosis of 
Table 3 The distribution of pulmonary cysts in pneumothorax and non-pneumothorax groups and corresponding P values

\begin{tabular}{|c|c|c|c|}
\hline & $\begin{array}{l}\text { Pneumothorax group } \\
\text { [median (quartile)] }\end{array}$ & $\begin{array}{l}\text { Non-pneumothorax } \\
\text { group [median (quartile)] }\end{array}$ & P value \\
\hline Long-axis diameter of the largest cysts (mm) & $46(28,54)$ & $28(12.5,35.5)$ & 0.028 \\
\hline Short-axis diameter of the largest cysts $(\mathrm{mm})$ & $24(16.8,36.5)$ & $13(7,16.5)$ & 0.004 \\
\hline Volume of the largest cysts $\left(\mathrm{mm}^{3}\right)$ & $14,178.5(4462.3,35,189.5)$ & $1571(356,5438.5)$ & 0.005 \\
\hline Total long-axis diameter of the cysts with long-axis diameter $\geq 20 \mathrm{~mm}(\mathrm{~mm})$ & $149(71.3,515.3)$ & $156.5(26,403.3)$ & 0.691 \\
\hline Total short-axis diameter of the cysts with long-axis diameter $\geq 20 \mathrm{~mm}(\mathrm{~mm})$ & $77(24.5,319)$ & $96(11.8,209.8)$ & 0.691 \\
\hline Total volume of the cysts with long-axis diameter $\geq 20 \mathrm{~mm}\left(\mathrm{~mm}^{3}\right)$ & $25,539.62(4818.8,109,694.7)$ & $23,126.97(2221.2,61,020.9)$ & 0.760 \\
\hline \multicolumn{4}{|l|}{ Right lung } \\
\hline Total number of the cysts in the right lung & $49(25,96.5)$ & $28(8.5,56.5)$ & 0.117 \\
\hline Number of the cysts with long-axis diameter $\leq 10 \mathrm{~mm}$ in the right lung & $36(20.8,64.8)$ & $22(8,45)$ & 0.171 \\
\hline Number of the cysts with long-axis diameter $10-20 \mathrm{~mm}$ in the right lung & $9(2,16)$ & $2(0,11)$ & 0.215 \\
\hline Number of the cysts with long-axis diameter $\geq 20 \mathrm{~mm}$ in the right lung & $2(1,9.8)$ & $0(0,4)$ & 0.103 \\
\hline $\begin{array}{l}\text { Number of the mediastinal subpleural cysts with long-axis diameter } \leq 10 \mathrm{~mm} \text { in } \\
\text { the right lung }\end{array}$ & $9(6.5,12.8)$ & $6(3,9.5)$ & 0.154 \\
\hline $\begin{array}{l}\text { Number of the mediastinal subpleural cysts with long-axis diameter } 10-20 \mathrm{~mm} \text { in } \\
\text { the right lung }\end{array}$ & $3(1.8,6)$ & $1(0,5)$ & 0.375 \\
\hline $\begin{array}{l}\text { Number of the mediastinal subpleural cysts with long-axis diameter } \geq 20 \mathrm{~mm} \text { in } \\
\text { the right lung }\end{array}$ & $1(0,6)$ & $0(0,1.5)$ & 0.182 \\
\hline $\begin{array}{l}\text { Number of the chest wall subpleural cysts with long-axis diameter } \leq 10 \mathrm{~mm} \text { in } \\
\text { the right lung }\end{array}$ & $12.5(6.5,29)$ & $9(1.5,15.5)$ & 0.177 \\
\hline $\begin{array}{l}\text { Number of the chest wall subpleural cysts with long-axis diameter } 10-20 \mathrm{~mm} \text { in } \\
\text { the right lung }\end{array}$ & $1.5(0.8,4.3)$ & $0(0,3)$ & 0.226 \\
\hline $\begin{array}{l}\text { Number of the chest wall subpleural cysts with long-axis diameter } \geq 20 \mathrm{~mm} \text { in } \\
\text { the right lung }\end{array}$ & $1(0,1.3)$ & $0(0,0.5)$ & 0.191 \\
\hline $\begin{array}{l}\text { Number of the interlobar subpleural cysts with long-axis diameter } \leq 10 \mathrm{~mm} \text { in } \\
\text { the right lung }\end{array}$ & $6(3.5,10.3)$ & $1(0,7)$ & 0.223 \\
\hline $\begin{array}{l}\text { Number of the interlobar subpleural cysts with long-axis diameter } 10-20 \mathrm{~mm} \text { in } \\
\text { the right lung }\end{array}$ & $0(0,3.3)$ & $0(0,1.5)$ & 0.420 \\
\hline $\begin{array}{l}\text { Number of the interlobar subpleural cysts with long-axis diameter } \geq 20 \mathrm{~mm} \text { in } \\
\text { the right lung }\end{array}$ & $1(0,2.3)$ & $0(0,1)$ & 0.292 \\
\hline \multicolumn{4}{|l|}{ Left lung } \\
\hline Total number of the cysts in the left lung & $52(17.8,85.3)$ & $16(8.5,71.5)$ & 0.246 \\
\hline Number of the cysts with long-axis diameter $\leq 10 \mathrm{~mm}$ in the left lung & $34.5(14,59.8)$ & $15(4,53.5)$ & 0.307 \\
\hline Number of the cysts with long-axis diameter $10-20 \mathrm{~mm}$ in the left lung & $11.5(3.5,17)$ & $2(0.5,12)$ & 0.097 \\
\hline The number of the cysts with long-axis diameter $\geq 20 \mathrm{~mm}$ in the left lung & $2(0.8,8)$ & $1(0,7)$ & 0.592 \\
\hline $\begin{array}{l}\text { Number of the mediastinal subpleural cysts with long-axis diameter } \leq 10 \mathrm{~mm} \text { in } \\
\text { the left lung }\end{array}$ & $8(3,16.3)$ & $4(2,15)$ & 0.632 \\
\hline $\begin{array}{l}\text { Number of the mediastinal subpleural cysts with long-axis diameter } 10-20 \mathrm{~mm} \text { in } \\
\text { the left lung }\end{array}$ & $3.5(1.5,5.5)$ & $1(0,5)$ & 0.500 \\
\hline $\begin{array}{l}\text { Number of the mediastinal subpleural cysts with long-axis diameter } \geq 20 \mathrm{~mm} \text { in } \\
\text { the left lung }\end{array}$ & $1(0,2.5)$ & $0(0,4.5)$ & 0.823 \\
\hline $\begin{array}{l}\text { Number of the chest wall subpleural cysts with long-axis diameter } \leq 10 \mathrm{~mm} \text { in } \\
\text { the left lung }\end{array}$ & $11.5(4.3,19.5)$ & $7(1,21.5)$ & 0.485 \\
\hline $\begin{array}{l}\text { Number of the chest wall subpleural cysts with long-axis diameter } 10-20 \mathrm{~mm} \text { in } \\
\text { the left lung }\end{array}$ & $4(0,5)$ & $2(0,3)$ & 0.145 \\
\hline $\begin{array}{l}\text { Number of the chest wall subpleural cysts with long-axis diameter } \geq 20 \mathrm{~mm} \text { in } \\
\text { the left lung }\end{array}$ & $0(0,3.5)$ & $0(0,1.5)$ & 0.408 \\
\hline $\begin{array}{l}\text { Number of the interlobar subpleural cysts with long-axis diameter } \leq 10 \mathrm{~mm} \text { in } \\
\text { the left lung }\end{array}$ & $3.5(1,5.5)$ & $0(0,4.5)$ & 0.194 \\
\hline $\begin{array}{l}\text { Number of the interlobar subpleural cysts with long-axis diameter } 10-20 \mathrm{~mm} \text { in } \\
\text { the left lung }\end{array}$ & $1(0,2)$ & $0(0,1)$ & 0.153 \\
\hline $\begin{array}{l}\text { Number of the interlobar subpleural cysts with long-axis diameter } \geq 20 \mathrm{~mm} \text { in } \\
\text { the left lung }\end{array}$ & $0(0,0.3)$ & $0(0,1)$ & 0.791 \\
\hline Bothlungs & & & \\
\hline
\end{tabular}


Table 3 (continued)

\begin{tabular}{|c|c|c|c|}
\hline & $\begin{array}{l}\text { Pneumothorax group } \\
\text { [median (quartile)] }\end{array}$ & $\begin{array}{l}\text { Non-pneumothorax } \\
\text { group [median (quartile)] }\end{array}$ & P value \\
\hline Total number of the cysts in both lungs & $135(39,169.5)$ & $44(18,138.5)$ & 0.057 \\
\hline Number of the cysts with long-axis diameter $\leq 10 \mathrm{~mm}$ in both lungs & $81.5(32.5,135)$ & $36(12.5,100.5)$ & 0.161 \\
\hline Number of the cysts with long-axis diameter $10-20 \mathrm{~mm}$ in both lungs & $17(5.5,33.5)$ & $5(0.5,23)$ & 0.116 \\
\hline Number of the cysts with long-axis diameter $\geq 20 \mathrm{~mm}$ in both lungs & $5(2,19)$ & $1(0,11)$ & 0.065 \\
\hline $\begin{array}{l}\text { Number of the mediastinal subpleural cysts with long-axis diameter } \leq 10 \mathrm{~mm} \text { in } \\
\text { both lungs }\end{array}$ & $21(9.8,27.5)$ & $12(5,27.5)$ & 0.324 \\
\hline $\begin{array}{l}\text { Number of the mediastinal subpleural cysts with long-axis diameter } 10-20 \mathrm{~mm} \text { in } \\
\text { both lungs }\end{array}$ & $7.5(3.5,11.5)$ & $2(0.5,10)$ & 0.226 \\
\hline $\begin{array}{l}\text { Number of the mediastinal subpleural cysts with long-axis diameter } \geq 20 \mathrm{~mm} \text { in } \\
\text { both lungs }\end{array}$ & $1.5(0.8,8)$ & $1(0,5.5)$ & 0.398 \\
\hline $\begin{array}{l}\text { Number of the chest wall subpleural cysts with long-axis diameter } \leq 10 \mathrm{~mm} \text { in } \\
\text { both lungs }\end{array}$ & $26(13.3,45.8)$ & $16(4,38.5)$ & 0.215 \\
\hline $\begin{array}{l}\text { Number of the chest wall subpleural cysts with long-axis diameter } 10-20 \mathrm{~mm} \text { in } \\
\text { both lungs }\end{array}$ & $5(1,10.3)$ & $2(0,5.5)$ & 0.189 \\
\hline $\begin{array}{l}\text { Number of the chest wall subpleural cysts with long-axis diameter } \geq 20 \mathrm{~mm} \text { in } \\
\text { both lungs }\end{array}$ & $1.5(0,6)$ & $0(0,2.5)$ & 0.248 \\
\hline $\begin{array}{l}\text { Number of the interlobar subpleural cysts with long-axis diameter } \leq 10 \mathrm{~mm} \text { in } \\
\text { both lungs }\end{array}$ & $9(5.8,17.3)$ & $2(0,8.5)$ & 0.061 \\
\hline $\begin{array}{l}\text { Number of the interlobar subpleural cysts with long-axis diameter 10-20 } \mathrm{mm} \text { in } \\
\text { both lungs }\end{array}$ & $1(0.8,5.3)$ & $0(0,3)$ & 0.054 \\
\hline $\begin{array}{l}\text { Number of the interlobar subpleural cysts with long-axis diameter } \geq 20 \mathrm{~mm} \text { in } \\
\text { both lungs }\end{array}$ & $1(0,3.3)$ & $0(0,2)$ & 0.234 \\
\hline
\end{tabular}

BHD syndrome, pulmonary CT findings are the main indication for BHD syndrome that can prompt patients to undergo further examinations to determine the diagnosis. Many studies have shown that the prevalence of spontaneous pneumothorax in patients with BHD syndrome reaches $>60 \%[6,8,16,17]$. Additionally, the risk of pneumothorax in patients with BHD syndrome is 50 times that of family members without BHD syndrome [4]. In our study, $54 \%$ of the patients with BHD syndrome developed pneumothorax, of whom $43 \%$ had it twice or more times. We deemed that the high incidence of pneumothorax in patients with BHD syndrome, especially recurrent pneumothorax, was related to their lung cysts. Therefore, we carefully examined the patients' chest CT images and classified them according to the distribution and size of the lesions. We found that the long-axis diameter, short-axis diameter, and volume of the largest cyst were correlated with the occurrence of pneumothorax, especially the short-axis diameter and volume of the largest cyst. This finding may be related to the shape and tension of the capsule, because the short-axis diameter can better reflect tension of the cyst. For capsules of the same volume, the larger the short-axis diameter is, the closer the cyst is to the spheroid and the greater the tension is. As the tension increases, the risk of bursa rupture is higher under the same condition.
In our study, the cysts with long-axis diameter $\leq 10 \mathrm{~mm}$ were the most common in both lungs. However, we thought that cysts with long-axis diameter $\geq 20 \mathrm{~mm}$, especially the subpleural ones, were more characteristic, which could help to diagnose BHD. Toro et al.[2] found that the exon position of a BHD mutation was related to the number of lung cysts, as well as the size and volume of the largest cyst. This finding indicates that an FLCN mutation may play an important role in the occurrence of pneumothorax. Pathologically abnormal epithelial/ mesenchymal interactions may weaken the extracellular matrix of the visceral pleura, leading to pneumothorax [14].

The occurrence of pneumothorax in patients with BHD syndrome is not only related to the patient's lung lesions, but also related to the external environment and various inducements. Johannesma et al. [9] found that flying or diving-associated air pressure changes may increase the risk of pneumothorax for patients with BHD syndrome, and the risk of pneumothorax is higher during flight. It is suggested that BHD patients with presence of any clinical symptoms (such as shortness of breath or chest pain) during flight or shortly after air travel should receive a chest X-ray or CT examination to exclude pneumothorax. In our study, one patient developed pneumothorax after returning from a trip to Yunnan plateau region by plane and another patient developed pneumothorax 
after dumbbell lifting. We speculate that the occurrence of pneumothorax in these patients was related to the change in atmospheric pressure and thoracic pressure. For patients with recurrent pneumothorax, pleural closure/covering technology [18] or the combined intervention with mechanical and chemical pleurodesis [19] can effectively treat pneumothorax and reduce recurrence.

In our study, 4 patients developed lung tumors (including small cell lung cancer, adenocarcinoma, and alveolar cell tumor). There is limited information currently available about the incidence of lung cancer in patients with BHD syndrome. Notably, lung adenocarcinoma has been reported in heterozygous FLCN knockout mice [20]. Whether FLCN gene mutations increase the risk of tumorigenesis in BHD patients requires further investigation.

Chest CT findings of BHD syndrome are characterized by bilateral, multiple, irregular shaped cysts of various sizes with subpleural predominance. Our quantitative analysis of the number, size, and distribution of lung cysts showed that there was a correlation between lung cysts and the occurrence of pneumothorax. Clinicians (especially emergency department physicians and surgeons) need to obtain more information about the disease history and family history when treating patients with pneumothorax. For patients with suspected BHD syndrome, a chest $\mathrm{CT}$ examination should be used rather than X-ray for more comprehensive assessment of lung lesions, and gene testing and a visit to the dermatology clinic are recommended. Following early detection of this syndrome, the patients and their families should be followed up, given personalized advice on diving and other related exercises, and pay close attention to pneumothorax and renal tumors that may affect prognosis and quality of life.

There are some limitations of our study. First, our study was a small sample retrospective study, which may lead to potential bias, uncertainty and generality in our statistical results. Second, some patients had a history of pneumothorax, which may affect the characteristic morphology, distribution, and number of pulmonary cysts. Therefore, we will enroll more patients in prospective design studies in the future to better observe the characteristics of pulmonary cysts and explore their relationship with pneumothorax in patients with BHD.

\section{Conclusion}

BHD patients have specific pulmonary imaging findings, and the occurrence of pneumothorax in BHD patients is closely related to their pulmonary cystic lesions.

\section{Abbreviations}

BHD: Birt-Hogg-Dubé; CT: Computed tomography; FLCN: Folliculin.

\section{Acknowledgements \\ Not applicable.}

\section{Authors' contributions}

$J Y$ and WW were guarantors of integrity of the entire study and designed the study. JY wrote the manuscript. XH and GZ organized the clinical study. JY and $J \mathrm{~L}$ analyzed CT data. YG was responsible for data analysis. All authors read and approved the final manuscript.

\section{Funding}

This work is supported by National Natural Science Foundation of China (81501468). The recipient of this fund was Wei Wei, corresponding author of this study.

\section{Availability of data and materials}

The datasets used and/or analyzed during the current study are available from the corresponding author on reasonable request.

\section{Declarations}

\section{Ethics approval and consent to participate}

This study was approved by the Ethics Committee of the First Affiliated Hospital of University of Science and Technology of China, and the ethics code was 2021-RE-084.The written informed consent of study participants was not required and was waived, which was approved by the Ethics Committee of the First Affiliated Hospital of University of Science and Technology of China, and the ethics code was 2021-RE-084. The study protocol conforms to the ethical guidelines of the 2002 Declaration of Helsinki.

\section{Consent for publication}

Not applicable.

\section{Competing interests}

The authors declare that they have no competing interests.

\section{Author details}

${ }^{1}$ Department of Radiology, The First Affiliated Hospital of USTC, Division of Life Sciences and Medicine, University of Science and Technology of China, Hefei 230001, Anhui, China. ${ }^{2}$ Department of Respiratory, The First Affiliated Hospital of USTC, Division of Life Sciences and Medicine, University of Science and Technology of China, Hefei 230001, Anhui, China. ${ }^{3}$ GE Healthcare China, Pudong New Town, No.1, Huatuo Road, Shanghai 210000, China.

Received: 22 August 2021 Accepted: 20 January 2022

Published online: 07 February 2022

\section{References}

1. Noppen M, De Keukeleire T. Pneumothorax. Respiration. 2008;76:121-7.

2. Toro JR, Pautler SE, Stewart L, et al. Lung cysts, spontaneous pneumothorax, and genetic associations in 89 families with Birt-Hogg-Dubé syndrome. Am J Respir Crit Care Med. 2007;175:1044-53.

3. Pavlovich CP, Walther MM, Eyler RA, et al. Renal tumors in the Birt-HoggDubé syndrome. Am J Surg Pathol. 2002;26:1542-52.

4. Zbar B, Alvord WG, Glenn G, et al. Risk of renal and colonic neoplasms and spontaneous pneumothorax in the Birt-Hogg-Dubé syndrome. Cancer Epidemiol Biomark Prev. 2002;11:393-400.

5. Menko FH, van Steensel MA, Giraud S, et al. Birt-Hogg-Dubé syndrome: diagnosis and management. Lancet Oncol. 2009;10:1199-206.

6. Park HJ, Park CH, Lee SE, et al. Birt-Hogg-Dube syndrome prospectively detected by review of chest computed tomography scans. PLoS ONE. 2017;12:e170713.

7. Liu Y, Xu Z, Feng R, et al. Clinical and genetic characteristics of chinese patients with Birt-Hogg-Dubé syndrome. Orphanet J Rare Dis. 2017; 12:1-8.

8. Ding Y, Zhu C, Zou W, et al. FLCN intragenic deletions in Chinese familial primary spontaneous pneumothorax. Am J Med Genet A 2015; 167:1125-33. 
9. Johannesma PC, van de Beek I, van der Wel JW, et al. Risk of spontaneous pneumothorax due to air travel and diving in patients with Birt-HoggDube syndrome. Springerplus. 2016;5:1506.

10. Schmidt LS, Nickerson ML, Warren MB, et al. Germline BHD-mutation spectrum and phenotype analysis of a large cohort of families with BirtHogg-Dubé syndrome. Am J Hum Genet. 2005;76:1023-33.

11. Lee JE, Cha YK, Kim JS, et al. Birt-Hogg-Dube syndrome: characteristic CT findings differentiating it from other diffuse cystic lung diseases. Diagn Interv Radiol. 2017;23:354-9.

12. Furuya M, Tanaka R, Koga S, et al. Pulmonary cysts of Birt-Hogg-Dubé syndrome: a clinicopathologic and immunohistochemical study of 9 families. Am J Surg Pathol. 2012;36:589-600.

13. Koga S, Furuya M, Takahashi Y, et al. Lung cysts in Birt-Hogg-Dubé syndrome: histopathological characteristics and aberrant sequence repeats. Pathol Int. 2009;59:720-8.

14. Furuya M, Nakatani Y. Birt-Hogg-Dube syndrome: clinicopathological features of the lung. J Clin Pathol. 2013;66:178-86.

15. Tobino K, Hirai T, Johkoh T, et al. Differentiation between Birt-HoggDubé syndrome and lymphangioleiomyomatosis: quantitative analysis of pulmonary cysts on computed tomography of the chest in 66 females. Eur J Radiol. 2012;81:1340-6.

16. Kunogi M, Kurihara M, Ikegami TS, et al. Clinical and genetic spectrum of Birt-Hogg-Dube syndrome patients in whom pneumothorax and/or multiple lung cysts are the presenting feature. J Med Genet. 2010;47:281-7.

17. Gupta N, Kopras EJ, Henske EP, et al. Spontaneous pneumothoraces in patients with Birt-Hogg-Dubé syndrome. Ann Am Thorac Soc. 2017;14:706-13.

18. Kurihara M, Kataoka $H$, Ishikawa A, et al. Latest treatments for spontaneous pneumothorax. Gen Thorac Cardiovasc Surg. 2010;58:113-9.

19. Asban A, Raza SS, McLeod C, et al. Mechanical or chemical and mechanical pleurodesis for spontaneous pneumothorax: what is the most effective approach in preventing recurrence? A systematic review and meta-analysis. Eur J Cardio-thorac Surg. 2020;58:682-91.

20. Hartman TR, Nicolas E, Klein-Szanto A, et al. The role of the Birt-HoggDubé protein in mTOR activation and renal tumorigenesis. Oncogene. 2009;28:1594-604.

\section{Publisher's Note}

Springer Nature remains neutral with regard to jurisdictional claims in published maps and institutional affiliations.

Ready to submit your research? Choose BMC and benefit from:

- fast, convenient online submission

- thorough peer review by experienced researchers in your field

- rapid publication on acceptance

- support for research data, including large and complex data types

- gold Open Access which fosters wider collaboration and increased citations

- maximum visibility for your research: over 100M website views per year

At BMC, research is always in progress.

Learn more biomedcentral.com/submissions 